\title{
Not Merely Physical
}

\author{
Malcolm Garrett \\ Images\&Co, The Clarence Centre \\ 6 St. George's Circus \\ London SE1 6FE, UK \\ malcolm.garrett@images.co.uk
}

\section{ABSTRACT}

As a graphic designer working for many decades with the display of information across multiple media: in print, on screen and in physical spaces, I have been become increasingly interested in the inter-relationship of visual and virtual data. The way the mind shapes and connects information is no longer simply as artefacts that are solid, or linear, or locked in time. The mind now operates in increasingly fluid spaces. Designers are faced with the challenge of helping people make sense of information that can be disturbingly transient.

This has come as no real surprise to me, as even when designing in physical spaces I had always been concerned with the shape and context of a printed page, and with the format and orientation of a package, rather than just its surface decoration. I never really thought of print as two-dimensional, especially when working with the packaging of records which whilst being flat, are round and twosided, and thus have a multitude of possible ways of viewing them.

Later, working on computer screens in the early days of interactive media, I very soon realised that the design of websites (and other digital platforms) demanded something beyond the replication of flat pages, and that the term 'web page' is something of a deceptive misnomer, as these pages can neither be confined to a fixed display size, nor operate in any fixed plane, and now as we carry our devices with us at all times, nor in any fixed location.

What goes on behind the page, linking information effortlessly into virtual space, became for me the principal challenge when considering how that information might display, and the term 'information architecture', where the virtual has an inherent sense of structure that demands the creation of a mental map to navigate it, began to intrigue me and, moreover, informed the way I thought about interface design.
I am particularly interested in what goes on inside people's minds when simultaneously processing information from both geographic and digital sources. It is natural to think of the design of artefacts for mapping and wayfinding as creating physical snapshots of the mental processes at work in moving from one place to another. Looking ahead I envisage exciting challenges in overlaying physical spaces with contextual virtual information, which can both inform and entertain. NetPark in Southend is one such project that is a pointer towards a new view of how public spaces provide a platform for connecting to digital as well as physical activity.

I have moved from the idea of wayfinding as simply an aide to relocating people, to it being an opportunity for them to step outside the physical and into an enhanced space beyond. The exploration of social, historical and other contextual information, and hitherto unknown creative interventions, offer great opportunities for design in public spaces. These are similar in many ways to the worlds within which games developers have worked, and which are now finding their way into other information, entertainment and learning environments. The enormous potential for the utilisation of game play beyond gaming is what a proposed Museum of Electronic Games and Arts (MEGA) is intended to explore.

To illustrate some of this, reference will be made to a number of projects that I have personally been engaged in, including record packaging, enhanced information delivery on CD-ROM, website design and other interactive media development, the 'Legible London' mapping of London, bus timetabling and route mapping in Dublin, and more recently the 'platforming' of public parks as virtual/physical community spaces where multiple activities overlap and the enjoyment of real and virtual space takes many forms. 